
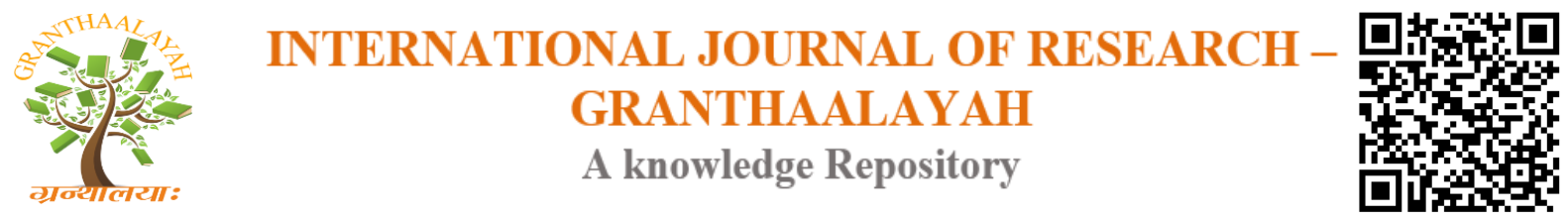

Social

\title{
EFFECT OF YOGIC EXERCISES AND MEDITATION ON EMOTIONAL WELLNESS AND SPIRITUAL WELLNESS OF WOMEN IN THOOTHUKUDI
}

\author{
Mrs. R. Thanga Selvam ${ }^{1}$, Mrs. D. Shunmuga SelvaSivaSankari ${ }^{2}$, Dr. A. Nagalakshmi ${ }^{3}$ \\ ${ }^{1}$ Assistant Professor of Biological Science, Annammal College of Education for Women, \\ Tiruchendur Road, Thoothukudi - 628003, INDIA \\ ${ }^{2}$ Assistant Professor of Mathematics, Annammal College of Education for Women, \\ Tiruchendur Road, Thoothukudi - 628003, INDIA \\ ${ }^{3}$ Director of Physical Education, Annammal College of Education for Women, \\ Tiruchendur Road, Thoothukudi - 628003, INDIA
}

DOI: https://doi.org/10.29121/granthaalayah.v4.i9(SE).2016.2511

\begin{abstract}
Today, yoga is considered as an alternative exercise approach to obtain personal health and wellbeing. Yoga's holistic methodology strives to unite one's body, mind, and spirit; it is a method of exercise mirrored in the physical, mental, and emotional benefits which result. The focus of this paper will highlight on the effect of yogic exercises and meditation on emotional wellness and spiritual wellness among women. The objectives of this study were to find out the level of emotional wellness and spiritual wellness of women before and after treatment and to find out the impact of yogic exercises and meditation on the emotional wellness and spiritual wellness of women. The investigators have adopted quasi-experimental method for this study. Results of this study show that there is significant difference between pretest and post test scores on emotional wellness and spiritual wellness of women before and after the yogic exercises and meditation.
\end{abstract}

Keywords:

Yogic Exercises, Meditation, Emotional Wellness, Spiritual Wellness.

Cite This Article: Mrs. R. Thanga Selvam, Mrs. D. Shunmuga SelvaSivaSankari, and Dr. A. Nagalakshmi, "EFFECT OF YOGIC EXERCISES AND MEDITATION ON EMOTIONAL WELLNESS AND SPIRITUAL WELLNESS OF WOMEN IN THOOTHUKUDI", International Journal of Research - Granthaalayah, Vol. 4, No. 9: SE (2016): 63-73.

\section{INTRODUCTION}

Yogic exercises and meditation is recognized as a form of mind-body medicine that integrates an individual's physical, mental and spiritual components to improve the different aspects of health. 
Practicing yoga and meditation as a means to manage and relieve stress helps individuals to lead an increased quality of life. It can release the emotional toxicity stored in the body. Just as changing thought patterns can influence the body, changing the position of the body can influence the mind and facilitate emotional and spiritual release. Yoga poses, breathing practices, and meditation release the constriction and free the flow of the vital life force energy known as prana. Yogic exercises and meditation helps to slow breath, quiet mind, and find peace, it can be beneficial physically, mentally, and emotionally.

Sri Aurobindo explains the importance of yoga in the following words - Yoga is a methodised effort towards self-perfection by the expression of the potentialities latent in the being and a union of the human individual with the universal and transcendent existence we see partially expressed in man and in the cosmos. It's really a comprehensive practice that integrates physical, mental and spiritual elements. Yoga can be viewed as a form of meditation that demands our full attention as we move from one asana (yoga position) to another. As we learn new ways of moving and responding to our body and mind, other areas of our life tend to shift and change as well. In a sense, we not only become more physically flexible, but our mind and approach to life may gain some needed flexibility as well.

"Meditation adds time to your day and energy to your body", says Sri.Sri.Ravishankarji. Keeping aside a few minutes to meditate daily can actually bring a few extra hours to do all the other things for one never finds time. When one meditates, creativity wells up from within. One starts gaining interest in doing things that are creative. Only a happy person can spread happiness and can be of help to others. This is where meditation helps.

\section{IMPACT OF YOGIC EXERCISES AND MEDITATION}

Practicing yoga can improve fitness and help to achieve or maintain a healthy weight. Properly executing yoga poses strengthens bones and muscles, enhances balance, and promotes flexibility and greater range of motion, all of which can help protect body against everyday injuries. Women who practice yoga and meditation tend to have lower body mass indexes and better control over their weight than those who do not practice yoga.

Yoga has shown a positive effect on variety of common psychiatric disorders such as: mild depression, sleep problems, schizophrenia (among patients using medication) and ADHD (among patients using medication). Stress reduction is a major health benefit of practicing yoga. Yoga's emphasis on breathing and meditation can help body's typical response to stress, lowering your blood pressure and decreasing production of stress hormones.

Meditation sharpens the mind by gaining focus and expands through relaxation. A sharp mind without expansion causes tension, anger and frustration. An expanded consciousness without sharpness can lead to lack of action/progress. The balance of a sharp mind and an expanded consciousness brings perfection. Meditation makes are aware that one's inner attitude determines one's happiness. 


\section{NEED FOR THE STUDY}

Man is an emotional entity. Emotion, being an integral part of the individual is an essential requirement for a balanced personality. The control and management of emotion are the important indicators for emotional development and balanced personality. Family life is a stage when a variety of mental health problems are more likely to develop among women compared to men. Woman is a multi-faceted, dynamic and uniquely influential part of our society and is forever striving for perfection in every aspect of life. However, to carry out all her roles with grace, flair and perfection, it is essential that women maintain good health, mental peace and poise in life. Yoga, among others, has been seen as a helpful method that can be used to protect women from mental illnesses. Yogic exercises and meditation involves physical postures, breathing, relaxation, and meditation. It helps to develop better moods, lower levels of anxiety and tension, better anger control, improved resilience, and enhanced mindfulness. These are just some of the many factors that are important in the prevention of psychological conditions in women.

Meditation and yoga improves women's alertness, personal values and beliefs. It helps building strength, character, good relationships with others, connection to the Nature and beyond. Emotional wellness brings compassion, love, sharing, caring and humanity to the business and work areas. Spiritual wellness brings self-awareness, contentment, self-acceptance, self regards, self-actualization, etc. Practicing yogic exercises and Meditation are beneficial for emotional and spiritual growth. Considering the above benefits of Yogic exercises for women, the investigators intended to study about the effect of yogic exercises on the emotional wellness and spiritual wellness of women in Thoothukudi.

\section{OBJECTIVES}

1) To construct a tool to assess the emotional wellness and spiritual wellness of women

2) To find out the emotional wellness and spiritual wellness of women before treatment

3) To find out the emotional wellness and spiritual wellness of women after treatment

4) To find out the level of emotional wellness of women before and after treatment

5) To find out the level of spiritual wellness of women before and after treatment

6) To find out the impact of yogic exercises and meditation on the emotional wellness and spiritual wellness of women

\section{HYPOTHESES}

1) There is no significant difference between pretest and post test scores on emotional wellness of women before and after the yogic exercises and meditation.

2) There is no significant difference between pretest and post test scores on spiritual wellness of women before and after the yogic exercises and meditation.

3) There is no significant difference between the gains scores on emotional wellness of women grouped on the basis of knowledge of yogic exercises.

4) There is no significant difference between the gains scores on emotional wellness of women grouped on the basis of knowledge of meditation. 
5) There is no significant difference between the gains scores on spiritual wellness of women grouped on the basis of knowledge of yogic exercises.

6) There is no significant difference between the gains scores on spiritual wellness of women grouped on the basis of knowledge of meditation.

\section{METHOD}

The investigator has adopted quasi-experimental method for this study.

\section{PROCEDURE}

Yogic exercises and meditation training were given by masters for two weeks to the subjects.

\section{TOOLS USED}

Questionnaires to assess Emotional Wellness and Spiritual Wellness were developed by the investigators and used for the data collection. Content validity was found seeking the help of educational experts.

\section{POPULATION AND SAMPLE}

Populations selected for this study were women. The sample consisted of 30 women in Thoothukudi area.

\section{STATISTICAL TECHNIQUES USED}

Following major statistical techniques were used by the investigators to analyse the data, Percentage analysis

Test of significance ( $t$ test)

\section{DATA ANALYSIS}

\section{Objective 1:}

To find out the level of emotional wellness and spiritual wellness of women before treatment

\begin{tabular}{|l|l|l|l|l|l|l|l|}
\hline \multirow{2}{*}{ Whole Group Before Treatment } & \multirow{2}{*}{ N } & \multicolumn{2}{l|}{ Low } & \multicolumn{2}{l|}{ Average } & \multicolumn{2}{l|}{ High } \\
\cline { 3 - 8 } & & Count & \% & Count & \% & Count & \% \\
\hline \multirow{2}{*}{ Emotional Wellness } & \multirow{2}{*}{30} & 4 & 13.3 & 20 & 66.7 & 6 & 20.0 \\
\cline { 3 - 8 } & & 6 & 20.0 & 17 & 56.7 & 7 & 23.3 \\
\hline Spiritual Wellness
\end{tabular}

It is inferred from the above table that, $13.3 \%, 66.7 \%$ and $20.0 \%$ of women have low, average and high level of emotional wellness respectively. $20.0 \%, 56.7 \%$ and $23.3 \%$ of women have low, average and high level of spiritual wellness respectively. 


\section{Objective 2:}

To find out the level of emotional wellness and spiritual wellness of women after treatment

\begin{tabular}{|l|l|l|l|l|l|l|l|}
\hline \multirow{2}{*}{ Whole Group After Treatment } & \multirow{2}{*}{$\mathbf{N}$} & \multicolumn{2}{l|}{ Low } & \multicolumn{2}{l|}{ Average } & \multicolumn{2}{l|}{ High } \\
\cline { 3 - 8 } & & Count & \% & Count & \% & Count & $\%$ \\
\hline Emotional Wellness & \multirow{2}{*}{30} & 0 & 0.0 & 11 & 36.7 & 19 & 63 \\
\cline { 3 - 9 } Spiritual Wellness & & 0 & 0.0 & 17 & 56.7 & 13 & 43.3 \\
\hline
\end{tabular}

It is inferred from the above table that, $36.7 \%$ and $63 \%$ of women have average and high level of emotional wellness respectively. $56.7 \%$ and $43.3 \%$ of women have average and high level of spiritual wellness respectively.

\section{Objective 3:}

To find out the level of emotional wellness of women before and after treatment

\begin{tabular}{|c|c|c|c|c|c|c|c|c|c|}
\hline \multirow{2}{*}{ Variables } & & & \multirow{2}{*}{$\mathbf{N}$} & \multicolumn{2}{|l|}{ Low } & \multicolumn{2}{|c|}{ Average } & \multicolumn{2}{|l|}{ High } \\
\hline & & & & Count & $\%$ & Count & $\%$ & Count & $\%$ \\
\hline $\begin{array}{l}\text { Emotional } \\
\text { Treatment) }\end{array}$ & Wellness & (Before & \multirow{2}{*}{30} & 4 & 13.3 & 20 & 66.7 & 6 & 20.0 \\
\hline $\begin{array}{l}\text { Emotional } \\
\text { Treatment) }\end{array}$ & Wellness & (After & & 0 & 0.0 & 11 & 36.7 & 19 & 63 \\
\hline
\end{tabular}

It is inferred from the above table that, $13.3 \%, 66.7 \%$ and $20.0 \%$ of women have low, average and high level of emotional wellness respectively. $36.7 \%$ and $63 \%$ of women have average and high level of emotional wellness respectively.

\section{Objective 4:}

To find out the level of spiritual wellness of women before and after treatment

\begin{tabular}{|c|c|c|c|c|c|c|c|c|c|}
\hline \multirow{2}{*}{\multicolumn{3}{|c|}{ Variables }} & \multirow{2}{*}{$\mathbf{N}$} & \multicolumn{2}{|l|}{ Low } & \multicolumn{2}{|c|}{ Average } & \multicolumn{2}{|l|}{ High } \\
\hline & & & & Count & $\%$ & Count & $\%$ & Count & $\%$ \\
\hline $\begin{array}{l}\text { Spiritual } \\
\text { Treatment) }\end{array}$ & Wellness & (Before & & 6 & 20.0 & 17 & 56.7 & 7 & 23.3 \\
\hline $\begin{array}{l}\text { Spiritual } \\
\text { Treatment) }\end{array}$ & Wellness & (After & U & 0 & 0.0 & 17 & 56.7 & 13 & 43.3 \\
\hline
\end{tabular}

It is inferred from the above table that, $20.0 \%, 56.7 \%$ and $23.3 \%$ of women have low, average and high level of spiritual wellness respectively. $56.7 \%$ and $43.3 \%$ of women have average and high level of spiritual wellness respectively.

\section{Hypothesis: 1}

There is no significant difference between pretest and post test scores on emotional wellness of women before and after the yogic exercises and meditation. 
Table 1:

\begin{tabular}{|l|l|l|l|l|}
\hline Emotional Wellness & $\mathbf{N}$ & Mean & Calculated 't' value & Remark \\
\hline Pre-test & 30 & 25.63 & \multirow{2}{*}{6.12} & \multirow{2}{*}{ Significant } \\
\hline Post-test & 30 & 31.57 & & \\
\hline
\end{tabular}

It is inferred from the above table that the calculated ' $t$ ' value (6.12) is greater than the table value (1.96) at 5\% level of significance. Therefore the null hypothesis is rejected. It shows that there is significant difference between pretest and post test scores on emotional wellness of women before and after the yogic exercises and meditation.

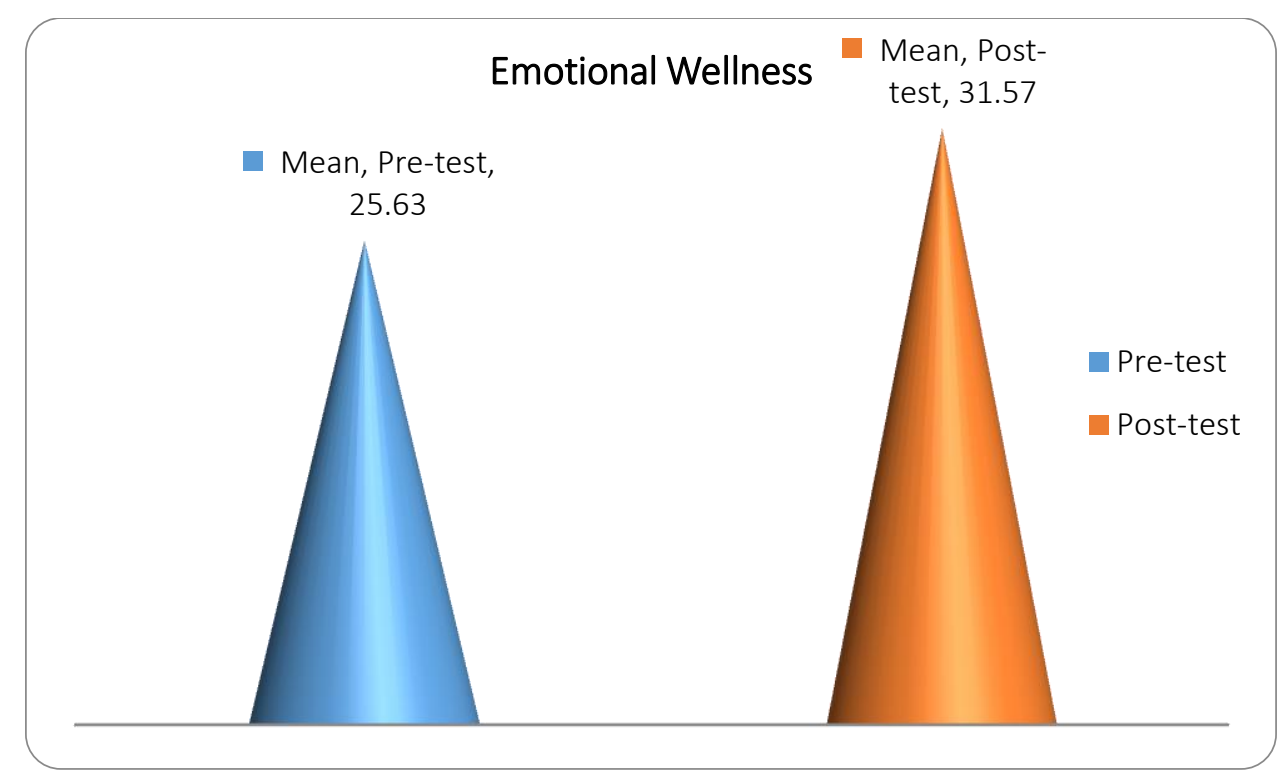

Graph 1:

\section{Hypothesis: 2}

There is no significant difference between pre test and post test scores on spiritual wellness of women before and after the yogic exercises and meditation.

Table 2:

\begin{tabular}{|l|l|l|l|l|}
\hline Spiritual Wellness & N & Mean & Calculated 't' value & Remark \\
\hline Pre-test & 30 & 30.87 & \multirow{2}{*}{4.08} & \multirow{2}{*}{ Significant } \\
\cline { 1 - 3 } Post-test & 30 & 34.7 & & \\
\hline
\end{tabular}

It is inferred from the above table that the calculated ' $t$ ' value (4.08) is greater than the table value (1.96) at 5\% level of significance. Therefore the null hypothesis is rejected. It shows that there is significant difference between pretest and post test scores on spiritual wellness of women before and after the yogic exercises and meditation. 


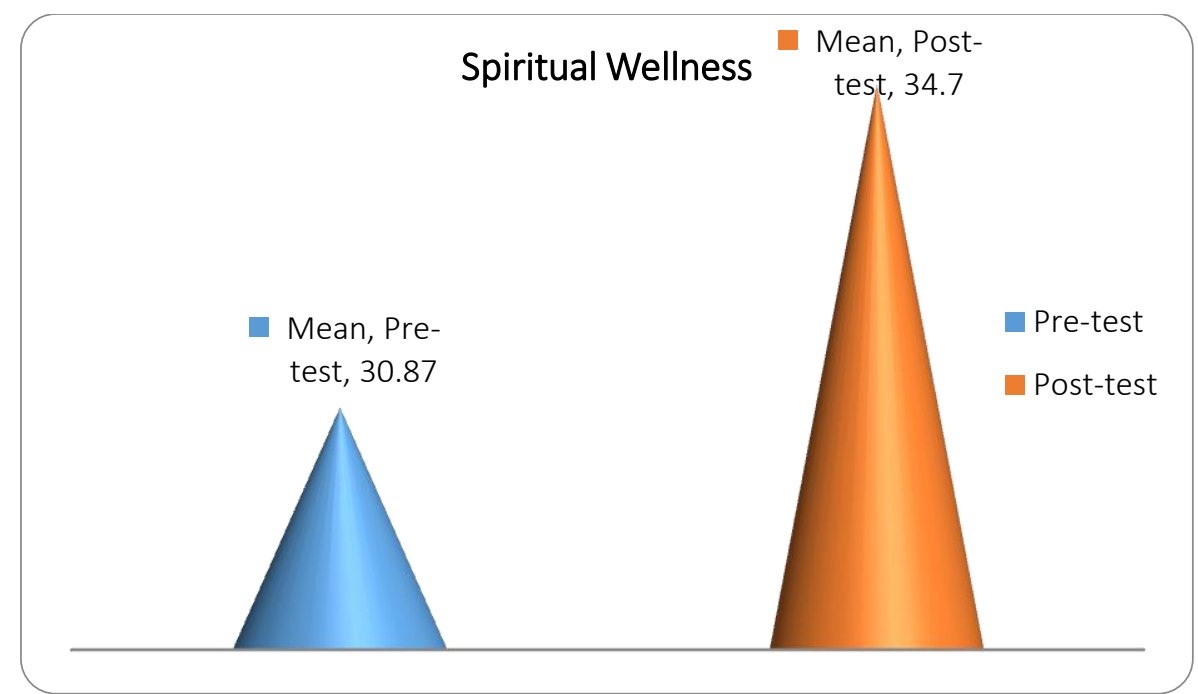

Graph 2:

\section{Hypothesis 3:}

There is no significant difference between the gain scores on emotional wellness of women grouped on the basis of knowledge of yogic exercises.

Table 3:

\begin{tabular}{|l|l|l|l|l|}
\hline Emotional Wellness & $\mathbf{N}$ & Mean & Calculated 't' value & Remark \\
\hline Knowledge of Yogic exercises & 12 & 7.25 & \multirow{2}{*}{1.113} & \multirow{2}{*}{ Not Significant } \\
\hline No knowledge of Yogic exercises & 18 & 5.06 & & \\
\cline { 1 - 2 }
\end{tabular}

It is inferred from the above table that the calculated ' $t$ ' value (1.113) is less than the table value (1.96) at 5\% level of significance. Therefore the null hypothesis is accepted. It shows that there is no significant difference between the gains scores on emotional wellness of women grouped on the basis of knowledge of yogic exercises.

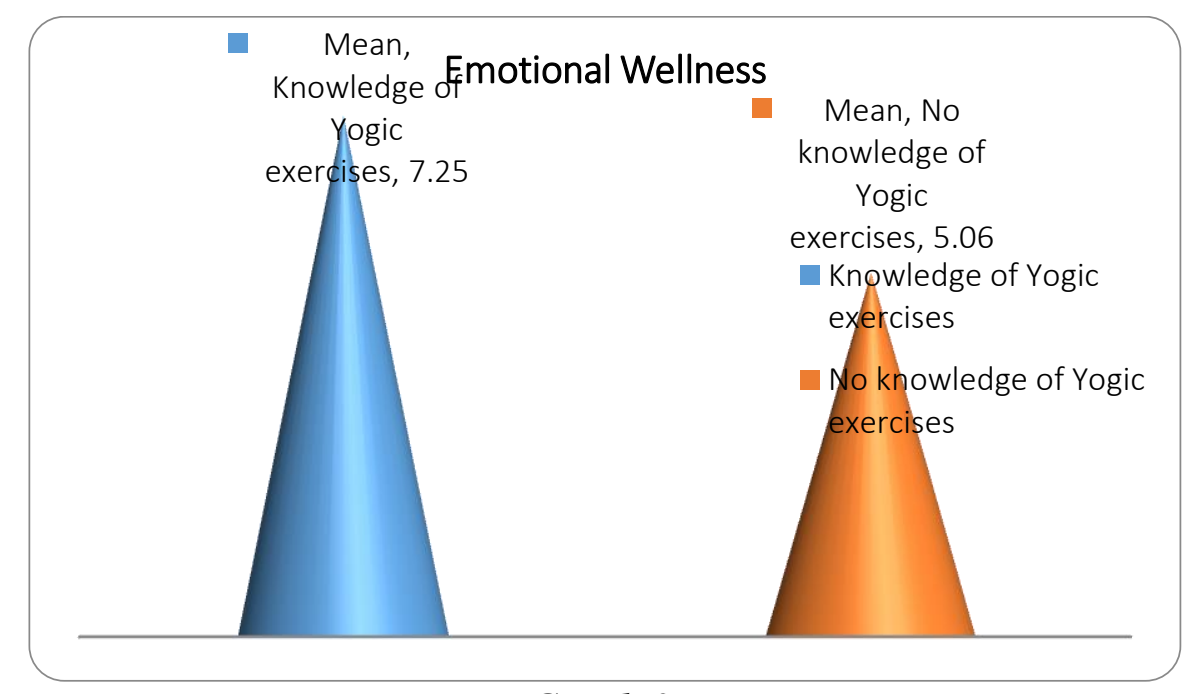

Graph 3: 


\section{Hypothesis 4:}

There is no significant difference between the gain scores on emotional wellness of women grouped on the basis of knowledge of meditation.

Table 4:

\begin{tabular}{|l|l|l|l|l|}
\hline Emotional Wellness & N & Mean & Calculated 't' value & Remark \\
\hline Knowledge of Meditation & 10 & 7.10 & \multirow{2}{*}{0.847} & \multirow{2}{*}{ Not Significant } \\
\cline { 1 - 3 } No knowledge of Meditation & 20 & 5.35 & & \\
\hline
\end{tabular}

It is inferred from the above table that the calculated ' $t$ ' value $(0.847)$ is less than the table value (1.96) at 5\% level of significance. Therefore the null hypothesis is accepted. It shows that there is no significant difference between the gains scores on emotional wellness of women grouped on the basis of knowledge of meditation.

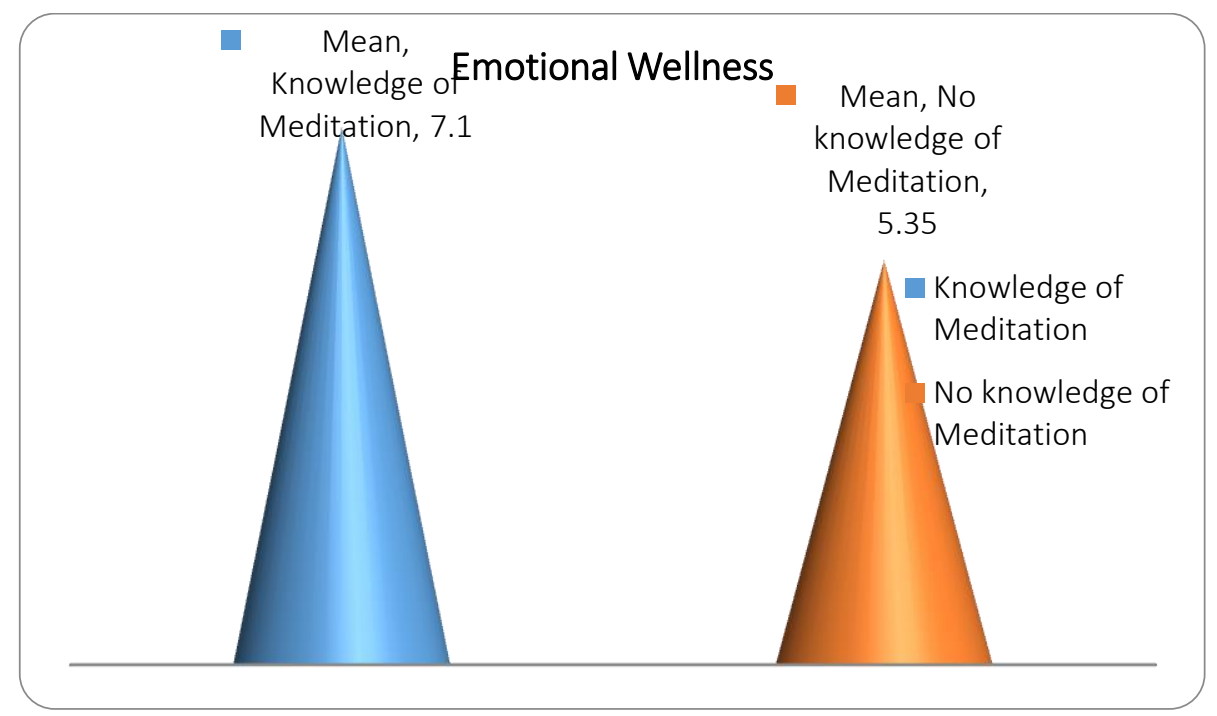

Graph 4:

\section{Hypothesis 5:}

There is no significant difference between the gain scores on spiritual wellness of women grouped on the basis of knowledge of yogic exercises.

Table 5:

\begin{tabular}{|l|l|l|l|l|}
\hline Spiritual Wellness & $\mathbf{N}$ & Mean & Calculated ' $t$ ' value & Remark \\
\hline Knowledge of Yogic exercises & 12 & 5.00 & \multirow{2}{*}{1.016} & \multirow{2}{*}{ Not Significant } \\
\hline No knowledge of Yogic exercises & 18 & 3.06 & & \\
\hline
\end{tabular}

It is inferred from the above table that the calculated ' $t$ ' value (1.016) is less than the table value (1.96) at 5\% level of significance. Therefore the null hypothesis is accepted. It shows that there is no significant difference between the gains scores on spiritual wellness of women grouped on the basis of knowledge of yogic exercises. 


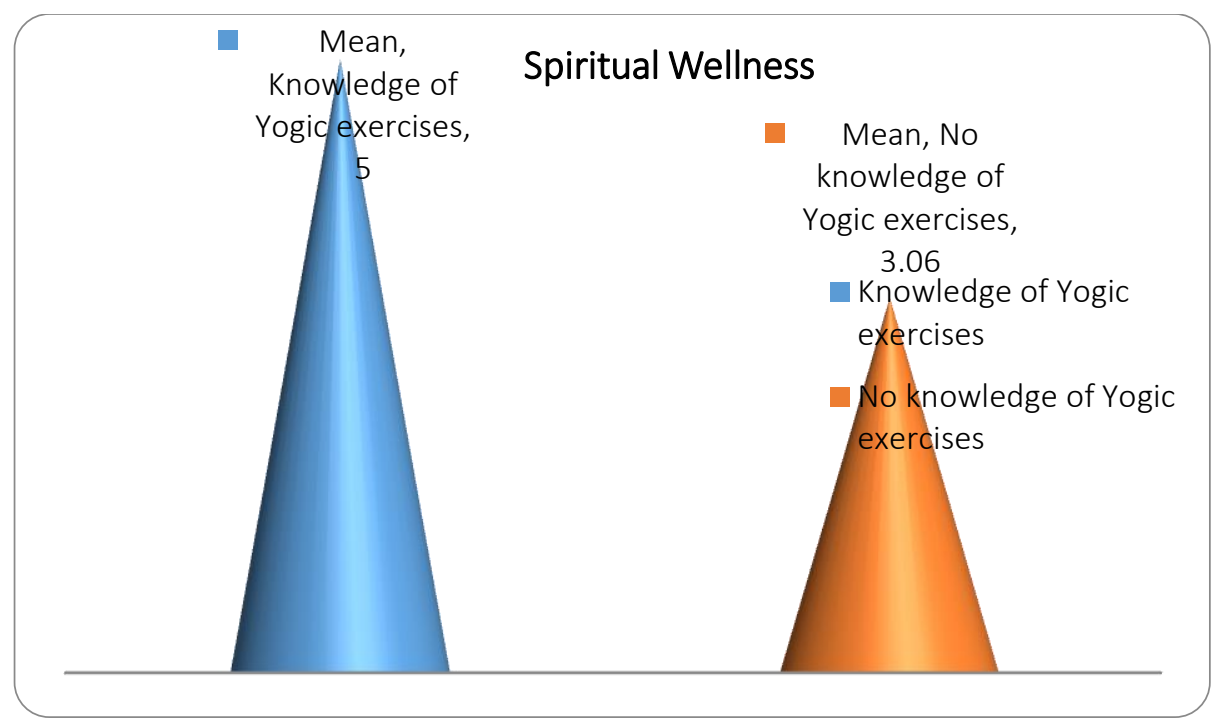

Graph 5:

\section{Hypothesis: 6}

There is no significant difference between the gain scores on spiritual wellness of women grouped on the basis of knowledge of meditation.

Table 6:

\begin{tabular}{|l|l|l|l|l|}
\hline Spiritual Wellness & $\mathbf{N}$ & Mean & Calculated 't' value & Remark \\
\hline Knowledge of Meditation & 10 & 5.30 & \multirow{2}{*}{1.110} & \multirow{2}{*}{ Not Significant } \\
\cline { 1 - 4 } No knowledge of Meditation & 20 & 3.10 & & \\
\hline
\end{tabular}

It is inferred from the above table that the calculated ' $t$ ' value (1.110) is less than the table value (1.96) at 5\% level of significance. Therefore the null hypothesis is accepted. It shows that there is no significant difference between the gain scores on spiritual wellness of women grouped on the basis of knowledge of meditation.

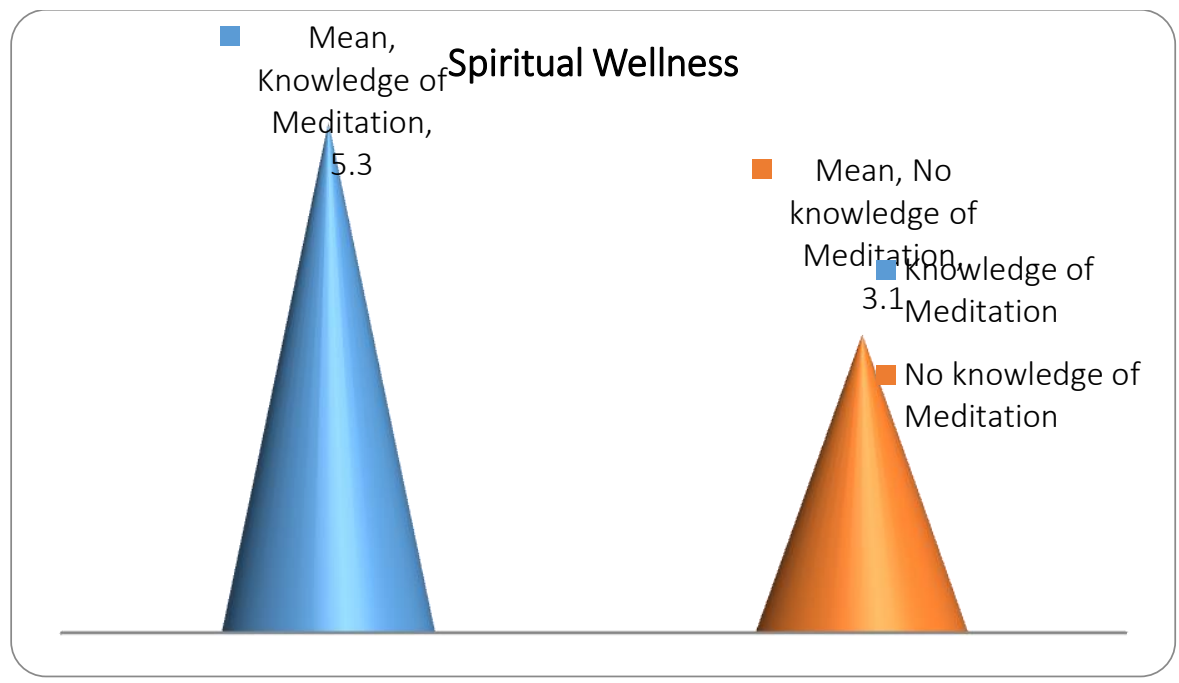

Graph 6: 


\section{INTERPRETATION}

The 't' test findings reveal that there is a significant difference between the pre test and post test scores on emotional wellness and spiritual wellness of women before and after training in Yogic exercises and meditation. This shows that the training by Yoga masters in physical exercises and meditation has impacted positively the emotional wellness and spiritual wellness of women. The training has helped women make better decisions and improved their critical thinking. It has also reduced their anxiety and depression.

There is no significant difference between women grouped on the basis of Yogic exercises and on the basis of meditation in their gain scores. This may be because a mere knowledge of Yogic exercises and meditation is by itself incapable of promoting the wellness of women. Only a regular practice of Yogic exercises and meditation can bring out an increase in the emotional wellness and spiritual wellness.

\section{CONCLUSION}

With the help of yoga, one can definitely put throw those unhealthy feelings on the wayside. According to the British Psychological Society, yoga involves concentration on the breath and body, which makes it a great way to soothe a person's mind and relieve worries. As a result, a person who does yoga is better able to achieve the pink of psychological health. Yogic exercises and meditation has an important role for building emotional-wellness and spiritual wellness among women in every social endeavour. Thus, incorporating Yoga in everyone's daily routine can unleash holistic and integrated personality.

\section{REFERENCES}

[1] K., Fuller. (n.d.). Ladies: Learn to Love Your Yoga. Retrieved May 18, 2016, from http://life.gaiam.com/article/ladies-learn-love-your-yoga.

[2] R., Shankar. (n.d.). Meditation for women: Take a break housewives!. Retrieved May 18, 2016, from http://www.artofliving.org/meditation/meditation-for-you/meditation housewives

[3] Golden, S. A. R. (2011). Problems and Prospectus of Distance Learning. Bharathidhasan University, 343, 344.

[4] Golden, S. A. R. (2011). Strategy For Success Of Human Beings:-Time Management.

[5] R., Khanna. (2010, September). The Importance of Yoga for Women. Retrieved May 18, 2016 from http://yogashaastra.blogspot.in/2010/09/importance-of-yoga-for-women.html

[6] R., Ojha. (2013, April). Role of Yoga and Meditation in the Empowerment of Women: an Ethical Perspective. IOSR Journal of Engineering (IOSRJEN), 3(4), 01-05. Retrieved May 18, 2016, from

http://www.iosrjen.org/Papers/vol3_issue4\%20(part-1)/A03410105.pdf

[7] Mercola. (2014, June 6). New Research Confirms Multiple Benefits of Yoga on Your Body and Mind. Retrieved May 18, 2016, from http://fitness.mercola.com/sites/fitness/archive/2014/06/06/yoga-health-benefits.aspx 
[8] M., Slocum. (2015, February 18). What Are the Health Benefits of Yoga for Women?. Retrieved May 18, 2016, from http://www.livestrong.com/article/411193-what-are-thehealth-benefits-of-yoga-for-women/

[9] R., Shankar. (n.d.). Yoga for Women. Retrieved May 18, 2016, from http://www.artofliving.org/in-en/yoga-for-women/yoga-women

[10] R., Shankar. (n.d.). Benefits of Meditation. Retrieved May 18, 2016, from http://www.artofliving.org/in-en/meditation-for-you/benefits-of-meditation. 